\title{
Outside the Box - Surgery for Aggressive Plasmacytoma in Scar
}

\author{
Ehud Fliss ${ }^{1}$, Arik Zaretski ${ }^{1}$, Yael Cohen ${ }^{1}$, Yuval Shapira ${ }^{1}$, Eyal Gur $^{1}$, and Ravit Yanko ${ }^{1}$ \\ ${ }^{1}$ Tel Aviv Sourasky Medical Center
}

May 31, 2020

\begin{abstract}
We describe the course of disease and multidisciplinary treatment of a multiple myeloma patient who presented with a lifethreatening plasmacytoma in-scar resistant to conventional treatment. She underwent wide resection with immediate free-flap reconstruction, allowing for early chemoradiotherapy and autologous bone marrow transplant. She survived additional 18 months following surgery.
\end{abstract}

\section{Hosted file}

Plasmacytoma in Scar - MANUSCRIPT.doc available at https://authorea.com/users/328173/ articles/455542-outside-the-box-surgery-for-aggressive-plasmacytoma-in-scar 


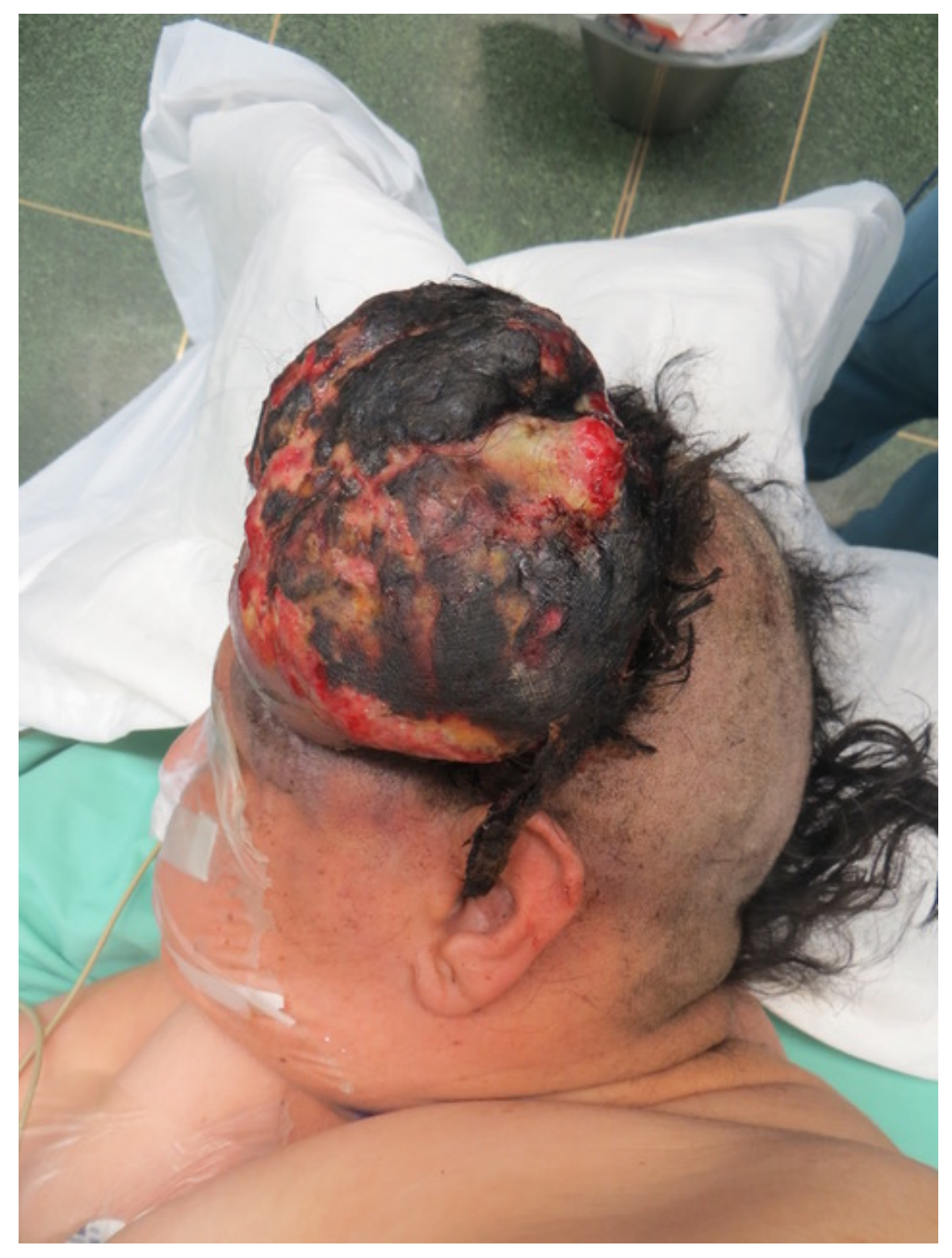



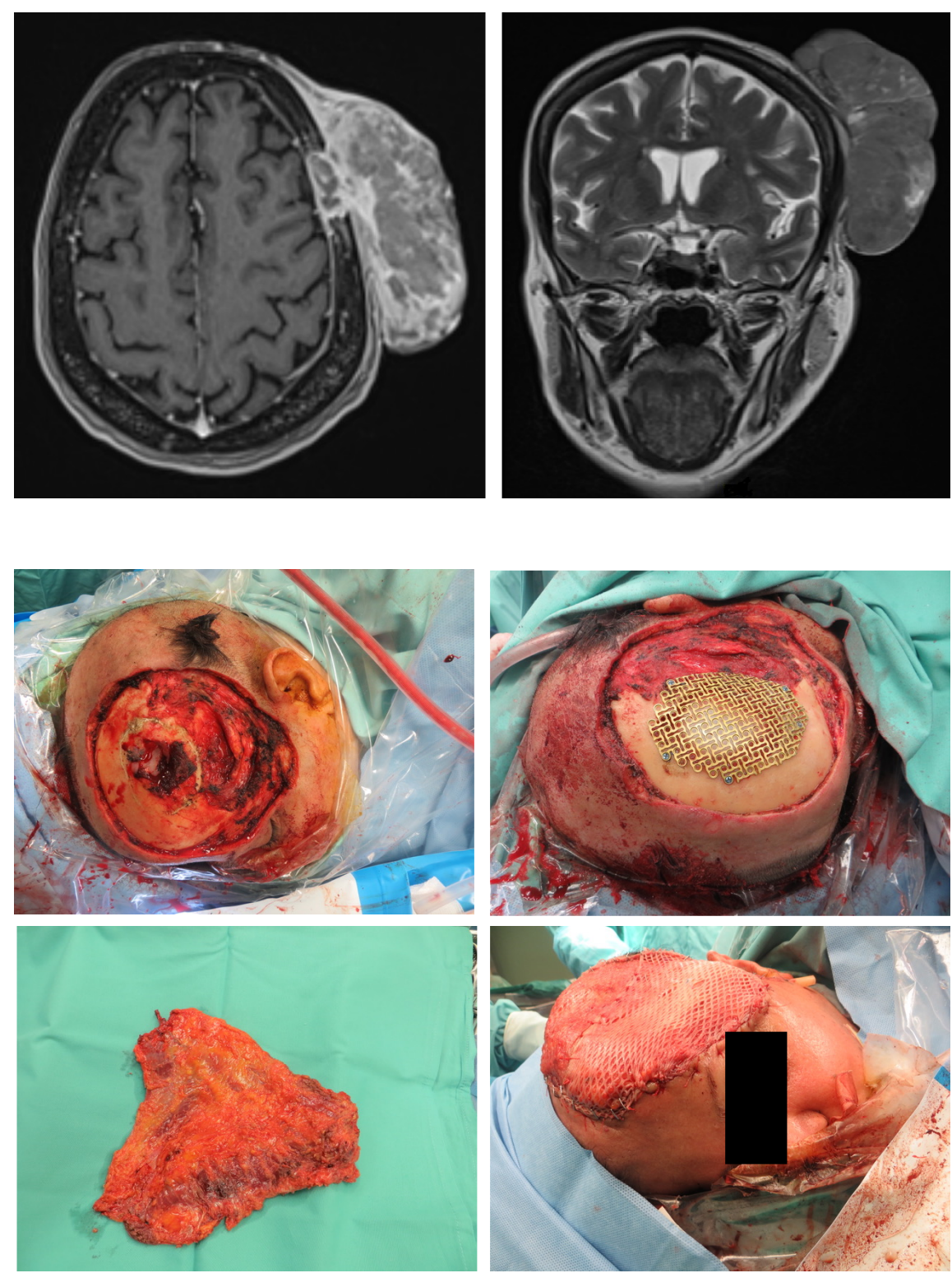


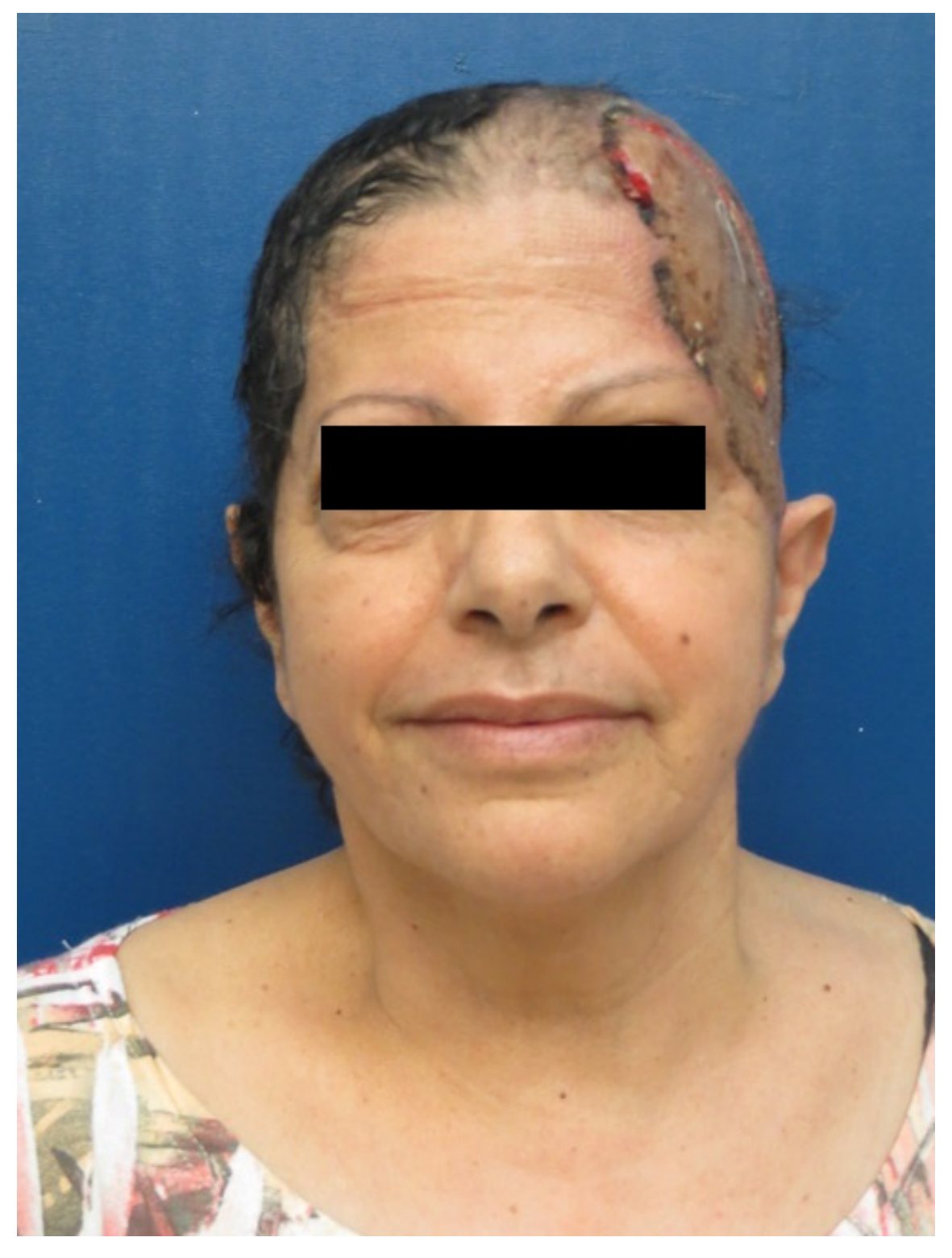

